the course of a lifetime. Scientists from all nations, working in all professional fields and scientific disciplines, are eligible to receive the award, which is named for NAPCRG's founder.

The UK has a very strong tradition of primary care research, and Professor Little is clearly one of the most influential researchers of his generation. He has a keen intellect, a prodigious work ethic, is incredibly creative, and has an engaging personal manner. Paul's extensive body of work is reflected in over 360 peer reviewed publications and in a career that spans more than 25 years. He is recognized as one of the most productive, creative, thoughtful, and respected primary care researchers in the world. Calling the United Kingdom home, Paul is Professor of Primary Care Research within Medicine at Southampton University

When I think of Paul, the words "gracious," "kind," and "charming" are top of mind. I know that he draws inspiration from and is committed to his Christian faith. Many of his stature can intimidate presenters with that familiar sense of dread when a raised hand signals an incisive question. But when Paul asks a question, you know it will not only inform and deepen the conversation but also be supportive and encouraging. He has mentored numerous trainees and faculty, building one of the most productive primary care research groups in the world at Southampton University.

Among many contributions to primary care research, one early, important one is "medicalization", the concept that primary care physicians shape patient perceptions of present and future illness. He has also done pioneering work to develop tools for antibiotic stewardship, ranging from non-antibiotic interventions to educational interventions to delayed prescriptions. His large randomized trial demonstrating the benefits of hand hygiene in reducing transmission of infection in the community is especially poignant now when the effects of COVID have made it impossible to shake Professor Little's hand in a congratulatory gesture of "job well done." His trials have been highly innovative, and were among the first to use the Internet and to incorporate pragmatic design elements. And of course, his research has been published the world's top journals including the The Lancet, The BMJ, JAMA, as well as Annals of Family Medicine, and continues have a tremendous impact on clinical practice.

Professor Little has made significant contributions to raising the profile of primary care research internationally and persuading funding bodies of the importance of applied research in primary care. Importantly, Paul has been a key member of European collaborative research teams that have done groundbreaking research on common acute respiratory infections in primary care including their epidemiology, diagnosis, and treatment. Paul has also been a longstanding supporter and contributor to NAPCRG as a regular attendee, mentor, lecturer and past member of the program committee.

Widely recognized, Professor Little was the first general practitioner to be awarded an MRC Clinician Scientist Fellowship in 1998. In 2011 he was elected as a Fellow of the Academy of Medical Sciences, a group that includes few GPs. Additionally, Professor Little is one of the few GPs to have been given 2 terms as an NIHR Senior Investigator. More recently, Professor Little was named a Commander of the British Empire by her majesty Queen Elizabeth for services to general practice research in 2018. And last year, Little received the Discovery Prize from the Royal College of General Practitioners. Clearly, Professor Little has had a deep and wide impact on primary care research and practice, and is most deserving of the NAPCRG Wood Award.

Mark Ebell, MD, MS

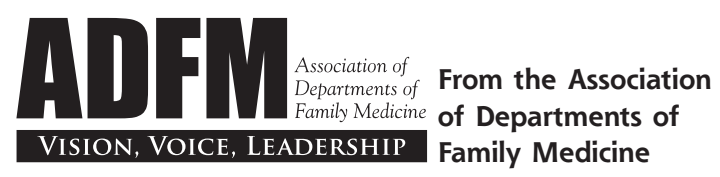

Ann Fam Med 2021;19:92-93. https://doi.org/10.1370/afm.2662.

\section{ONGOING CONSIDERATION OF GROWING THE LEADERSHIP FOR THE DISCIPLINE} Considering High-Level Leadership Positions

The landscape for the job of an academic department chair is not the same as it was 5 or 10 years ago. One major difference is that the clinical mission of academic medical systems has become increasingly prioritized (or at least its contribution to the budget has). Similarly, with health systems' increased recognition of the role of a strong primary care network, creation of service lines, and the employment of greater numbers of primary care physicians, the role of a health system leader looks different as well. With these realities in mind, ADFM has made a commitment to developing family physicians to be high-level leaders in health systems of all types. Integral to this commitment is prioritizing the development of women and those with backgrounds underrepresented in medicine (URiM) ${ }^{1}$.

If you are considering a high-level academic or other leadership position, there are many things to consider. A few important issues are:

1) Your "fit" in the role you seek and the organization you are considering: What are the goals of the 
organization? What is the top leadership's (dean, CEO) style of management? What is their agenda? How do your style, goals, and agenda align with theirs?

2) Understanding the financial aspects of the organization is essential: What are the important aspects of the local marketplace? What are the relevant revenue streams? How do institutional funds flow? How is the budget developed and used?

3) What are the lines of authority as well as accountability for the budget and personnel you will be relying on to get the job done?

4) These are very political positions. To be successful, it is essential to navigate the people and personalities that form the politics.

5) What is the role and perception of family medicine in the health system/college of medicine?

6) Developing good relationships with other chairs/ peers is important. Who can be your natural partners and key collaborators in the institution?

ADFM has developed an aspirational leadership competencies list (https://adfm.org/media/1840/adfmcompetencies-for-chairs-feb-4-2020.pdf). It's "aspirational" in that no one, or at most very few people, have all of the skills listed. It can be best used as a guide to help you consider your leadership developmental needs.

\section{LEADS Fellowship Expansion and Leadership Resources}

ADFM, along with the rest of the family of Family Medicine, has put together a number of resources and programs for developing leaders. In July 2019, we shared how we expanded our Leadership Education for Academic Success (LEADS) Fellowship and described our plans for further expansion, to help meet the need to train family medicine leaders for the changing dynamics of health systems described above ${ }^{2}$.

With support from the ABFM Foundation, we held a summit in November 2019 to gather input from a variety of stakeholders to envision what a robust leadership development program for mid- to late-career family physicians would look like. We collectively considered the aims of the program (audience, eligibility criteria, intended outcomes), program logistics (size, length, cost, staffing), content and curricular offerings, mentorship structure, incorporation of alumni, and program evaluation.

With the outcomes of the summit in hand, we proceeded to finalize plans to grow and expand the LEADS Fellowship. With added gratitude to the ABFM Foundation for agreeing to support start-up costs over the next 3-4 years, the LEADS Fellowship will enroll to up to 40 mid- to late-career family medicine leaders as fellows with a special interest in attracting women, those with backgrounds underrepresented in medicine
(URiM), and others who are underrepresented in academic medicine and health system leadership positions, such as those from rural areas. We anticipate that most applicants will be physicians, but do not exclude other leaders (eg, PhDs, administrators and other health professions in leadership roles).

The goal of the fellowship is to train pluripotent family medicine leaders to have the skills/understanding to perform well in a high-level leadership position (eg, department chair, service line leader) and who would also be competitive for other leadership positions beyond the scope of their current role within academics or health systems. The LEADS Fellowship will highlight strategic career planning and emphasize skills to engage in high level decision making in collaboration with other leaders in academic health systems (eg the pedagogical revolution, role of QI, etc). It is designed to be complimentary to a variety of existing programs and yet offer something unique with an intent to provide high level leaders for the discipline. The content is structured around the ADFM leadership competencies (noted above) and is designed to be cohort-responsive, though some standing content will be set ahead of time.

We are beginning to plan this expansion, preparing for a paid fellowship director position and designated staff support in charge of the program. More information will be coming!

\section{Other Opportunities and Resources}

Those interested in formal programming but not ready for or interested in LEADS should check out the listing of opportunities across the family, hosted by STFM, and available here: https://www.stfm.org/ facultydevelopment/otherfacultytraining/leadership developmentopportunities/overview/.

Additionally, ADFM has a number of other open access resources for new chairs and others in leadership positions available here: https://adfm.org/ resources/new-chairs/. We recently put together a suggested reading list for anyone in leadership positions, shared by our members; you can find the list on this resources page.

Jobn Franko, $M D$, Myra Muramoto, $M D$,

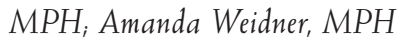

\section{References}

1. Coe C, Piggott C, Davis A, et al. Leadership pathways in academic family medicine: focus on underrepresented minorities and women. Fam Med. 2020;52(2):104-111. https://doi.org/10.22454/ FamMed.2020.545847.

2. Weidner A, Franko J, Davis A, Muramoto M. ADFM LEADS Fellowship: leadership education for academic development and success. Ann Fam Med. 2019;17(4):374-375. https://www.annfammed.org/ content/17/4/374. 